\title{
Fístula carótida cavernosa, reporte de un caso de difícil diagnóstico
}

\section{Carotid-cavernous fistula, report of a difficult case}

\author{
Sara Chica-Calderón ${ }^{1 *}$, María E. González-Alviar ${ }^{1}$ y Sergio Vargas-Vélez ${ }^{2,3}$ \\ ${ }^{1}$ Servicio de Oftalmología, Universidad de Antioquia; ${ }^{2}$ Neurorradiólogía, Docente Universidad de Antioquia; ${ }^{3}$ CediMed. Medellín, Colombia
}

\section{Resumen}

Se presenta el caso de una paciente de 64 años con síntomas inespecificos, de 7 meses de evolución, de diplopía y proptosis unilateral. Al examen físico muestra una marcada limitación de la abducción del recto lateral, pero en la resonancia magnética se observa principalmente un engrosamiento del recto medio. Se hace diagnóstico de oftalmopatía distiroidea por lectura de neurorradiólogo. Por no mejoría de la paciente con el tratamiento y continuidad de sus síntomas, se pide una relectura de la resonancia, en la que se encuentran signos de una fístula carotidocavernosa. El diagnóstico de proptosis es un reto en oftalmología. En general está causada por una oftalmopatía distiroidea, pero se debe pensar en otros diagnósticos en pacientes con signos inusuales y sin mejoría con el tratamiento estándar.

Palabras clave: Exoftalmos. Fístula carotidocavernosa. Conjuntivitis.

\begin{abstract}
We present the case of a 64-year-old female patient with a 7-month history of nonspecific symptoms of diplopia and unilateral proptosis. On physical examination there was a marked limitation of the abduction of the lateral rectus muscle, but magnetic resonance imaging (MRI) showed thickening of the medial rectus. An initial diagnosis of dysthyroid ophthalmopathy was made by a neuroradiologist. Despite treatment, there was no improvement of symptoms so a new evaluation of the MRI was requested, finding signs of a carotid-cavernous fistula. The diagnosis of proptosis is a challenge in ophthalmology. Usually, it is caused by dysthyroid ophthalmopathy; however, other diagnoses should be considered in patients with unusual signs and no improvement with standard treatment.
\end{abstract}

Keywords: Exophthalmos. Carotid-cavernous sinus fistula. Conjunctivitis.

\section{Introducción}

Las fístulas carotidocavernosas son comunicaciones anómalas entre la arteria carótida y el seno cavernoso, directamente o mediante ramas intradurales de la arteria carótida interna o externa, y generan un cortocircuito arteriovenoso. Pueden ser de origen espontáneo (congénitas, degenerativas, infecciosas) o más comúnmente traumáticas (hasta en un $75 \%$ de los casos). Barrow, et al. ${ }^{1}$ las clasifican, según los hallazgos angiográficos, en dos tipos: directas (tipo A) e indirectas o durales (tipos B, C y D) ${ }^{2}$. Desde el punto de vista
Fecha de recepción: 08-07-2019 Universidad de Antioquia, 050010 E-mail: sarischica @ hotmail.com
Disponible en internet: 17-03-2021 Rev Mex Oftalmol. 2021;95(5):222-226

www.rmo.com.mx 0187-4519/C 2020 Sociedad Mexicana de Oftalmología. Publicado por Permanyer. Este es un artículo open access bajo la licencia CC BY-NC-ND (http://creativecommons.org/licenses/by-nc-nd/4.0/). 
fisiopatológico hay una disfunción hemodinámica dentro del seno cavernoso con efectos congestivos e isquémicos ${ }^{1,3,4}$.

Las fístulas de alto flujo o directas se producen por la rotura de la arteria carótida interna en el interior del seno cavernoso. El cuadro clínico es dramático y se producen principalmente por trauma o por rotura de un aneurisma, y con menos frecuencia tras osteotomías tipo Le Fort I. Las de bajo flujo o indirectas ocurren por rotura, en general espontánea, de ramas de pequeño calibre de la arteria carótida interna o externa y del seno cavernoso. La causa de estas fístulas aún es controvertida. Una hipótesis señala la rotura de las paredes delgadas de las arterias durales que atraviesan el seno cavernoso; otra afirma que se desarrollan en respuesta a una trombosis venosa espontánea en el seno cavernoso ${ }^{3}$.

Son fístulas de muy difícil diagnóstico por su poca especificidad y por ser indolentes. Se presentan con mayor frecuencia en mujeres perimenopáusicas. Se atribuyen a numerosas causas, como anomalías congénitas, hipertensión venosa espontánea por trombosis, arteriosclerosis, enfermedades del colágeno, arteritis sifilítica y daño vascular iatrogénico.

Además de los síntomas compresivos, hay aumento del flujo, elevación de la presión intracavernosa y un flujo retrógrado que induce hipertensión venosa orbitaria, exoftalmos pulsátil, quemosis, congestión venosa retiniana y de vasos epiesclerales, cefalea y dolor orbitario. El soplo fronto-orbitario sincrónico con el pulso al reclinarse es patognomónico. Los principales nervios craneales afectados que limitan los músculos extraoculares son, por orden, el VI (contiguo a la arteria carótida interna, intracavernoso), el III, el IV y el V en sus ramos 1 y 2 (también intracavernosos); estos pueden sufrir compresión en patologías del seno cavernoso 0 adyacentes. La ptosis y la diplopía son precoces, siendo esta última el síntoma más habitual, por compresión de los músculos oculomotores. La gravedad depende de la cantidad de flujo y de la capacidad de drenaje venoso $0^{5-8}$.

En las imágenes suelen observarse dilatación de la vena orbitaria superior (no específica de fístula), abombamiento lateral del seno cavernoso, engrosamiento de los músculos extraoculares y flujo anormal en el seno cavernoso.

En ausencia de drenaje anterior o de dilatación de la vena oftálmica superior es fundamental realizar una angiorresonancia magnética con gadolinio. Si existe fístula se observa ingurgitación del seno, con una sensibilidad del $83 \%$ y una especificidad del $100 \%$. Sin embargo, esta técnica no puede definir las arterias implicadas ni el drenaje venoso cortical, por lo que resulta superior la angiografía convencional ${ }^{4}$.

Ante síntomas estables se hace observación. Un 30\% de los casos se solucionan mediante maniobras de compresión ${ }^{3}$. No obstante, conviene hacer un seguimiento cercano porque puede producirse un rápido deterioro visual o funcional de los nervios craneales por aumento de la presión intraocular, dado el retorno venoso retrógrado a través de la vena oftálmica superior.

El primer tratamiento exitoso fue realizado por el cirujano británico Travers, ligando la arteria carótida común; desde entonces, los avances terapéuticos han sido cuantiosos. El tratamiento debe ser urgente en casos de hipertensión intracraneal, déficits neurológicos, pérdida visual, accidentes isquémicos transitorios, etc.

La terapia endovascular varía según el tipo de fístula. La arteria puede ser sacrificada por encima y por debajo de la fístula («atrapamiento») con coils o con otros dispositivos. Otra opción es el abordaje transarterial, transvenoso o combinado para la oclusión de la fístula con agentes líquidos, coils o stents cubiertos (con preservación arterial). El empaquetamiento transvenoso del seno cavernoso con coils es más desafiante en las fístulas directas, comparado con el que se realiza en una malformación arteriovenosa dural; además, las fístulas tienen un alto volumen de flujo y requieren un empaquetamiento muy denso para inducir trombosis en la porción venosa. Los coils de fibra ofrecen ventajas en este aspecto, a pesar de su rigidez y tendencia al contragolpe del microcatéter. Existe el riesgo de migración de coils o de agentes líquidos del lado venoso al arterial, lo cual puede ser abordado con la colocación transarterial de un balón temporal que cruce la boca de la fístula. El tratamiento transvenoso de las fístulas arteriovenosas busca eliminarlas por completo, pero evitando que el resultado final sea un reflujo venoso intracraneal. Los stents cubiertos han sido usados en las fístulas carotidocavernosas por muchos autores cuando otras alternativas han fallado ${ }^{9,10}$.

\section{Caso clínico}

Mujer de 64 años que acude a la consulta porque «Tengo salido el ojo izquierdo y veo doble». Inicia hace 7 meses con sensación súbita de masa y presión en el ojo izquierdo, ardor, dolor, diplopía y edema bipalpebral. Niega antecedentes de trauma. Fue tratada en 

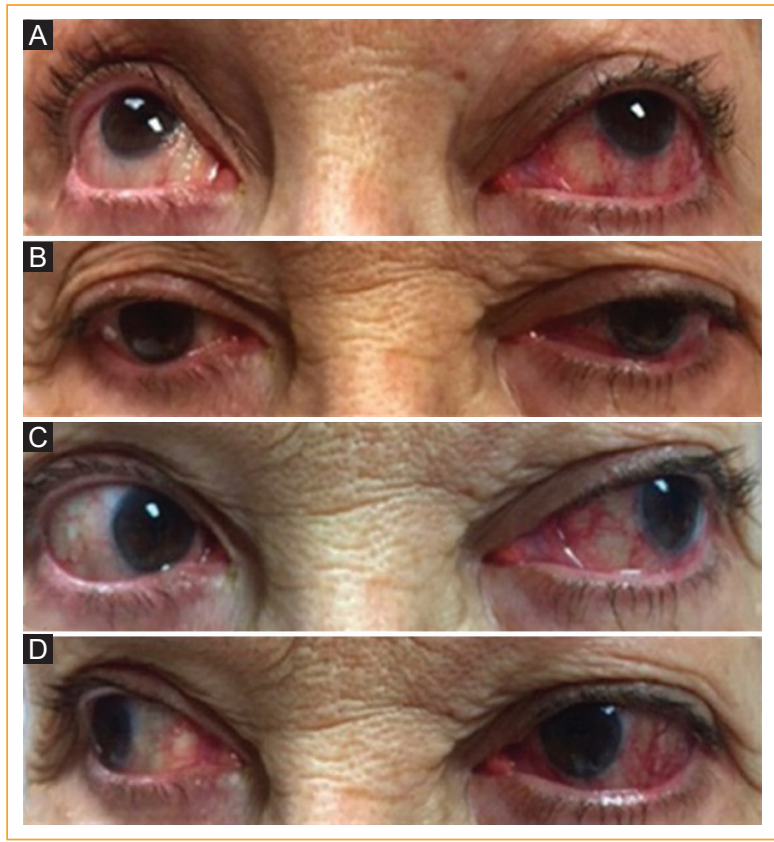

Figura 1. Examen clínico de la motilidad ocular. A: supraversión. B: infraversión. C: levoversión con marcada hipofunción del recto lateral. D: dextroversión.

múltiples ocasiones con esteroides, sin mejoría. En la revisión por sistemas refiere cefalea crónica. Al examen oftalmológico se encuentra una agudeza visual normal bilateral, anisocoria y defecto pupilar aferente en el ojo izquierdo. En el test de saturación al rojo se observa desaturación al rojo del $40 \%$ en el lado izquierdo. Motilidad ocular de ojo izquierdo con hipofunción del recto lateral de -4 (Fig. 1). Proptosis leve en el ojo izquierdo a la exoftalmometría. La biomicroscopía del ojo izquierdo muestra una marcada ingurgitación vascular nasal y temporal. La presión intraocular y la refracción son normales en ambos ojos. Al fondo de ojo se observan vasos tortuosos en la arcada temporal superior izquierda (Fig. 2).

Se realiza una resonancia magnética y en la secuencia T1 axial contrastada con saturación grasa se evidencia un engrosamiento difuso de los músculos extraoculares, principalmente del recto medial y respetando el tendón y la inserción musculares, además de proptosis ocular izquierda de $22 \mathrm{~mm}$ (Fig. 3 A). La primera lectura por neurorradiología sugiere una oftalmopatía distiroidea como primer diagnóstico. Debido a la discrepancia clinicorradiológica, con hipofunción del recto lateral al examen físico y engrosamiento principalmente del recto medial en la resonancia, además de no mejorar con esteroides, se solicita una nueva lectura

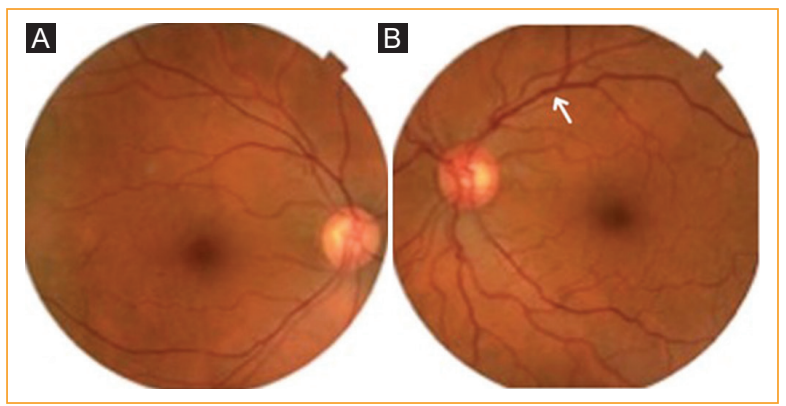

Figura 2. Fondo de ojo. A: ojo derecho normal. B: ojo izquierdo con tortuosidad en las arcadas temporales, principalmente superior (flecha).

por otro neurorradiólogo y se encuentran signos de fístula carotidocavernosa en las secuencias de angiorresonancia dados por una asimetría vascular en el seno cavernoso izquierdo, en comparación con el derecho, y una dilatación de la vena oftálmica superior izquierda (Fig. 3 B).

Tras estos hallazgos se realiza una angiografía cerebral para confirmar el diagnóstico (Fig. 4 A), en la que se demuestra una fístula carotidocavernosa de bajo flujo que, según la clasificación de Barrow ${ }^{3}$ (Fig. 3 C), es indirecta tipo $B$ nutrida por ramas durales del tronco meningohipofisiario de la carótida interna izquierda (Fig. 4 A). Se procede entonces a realizar una embolización con coils por vía endovenosa, a través del seno petroso inferior, hasta llegar al seno cavernoso (Fig. 4 B). El control angiográfico final (Fig. 4 C) muestra la completa oclusión de la fístula por los coils.

En el control a los 4 meses del tratamiento endovascular, la paciente se encuentra asintomática.

\section{Discusión}

Se trata de una paciente con proptosis unilateral crónica, limitación marcada del recto lateral, edema bipalpebral, congestión de vasos epiesclerales y vasos tortuosos al fondo de ojo. En la resonancia se encontró un engrosamiento difuso de los músculos extraoculares, principalmente del recto medial, y la impresión diagnóstica neurorradiológica inicial fue una oftalmopatía distiroidea. En una segunda lectura de la angiorresonancia se observan signos que sugieren una fístula carotidocavernosa, confirmada posteriormente mediante arteriografía.

Debido a la dificultad diagnóstica de los pacientes con fístula carotidocavernosa de bajo grado, y por tratarse de un cuadro clínico inespecífico, es 


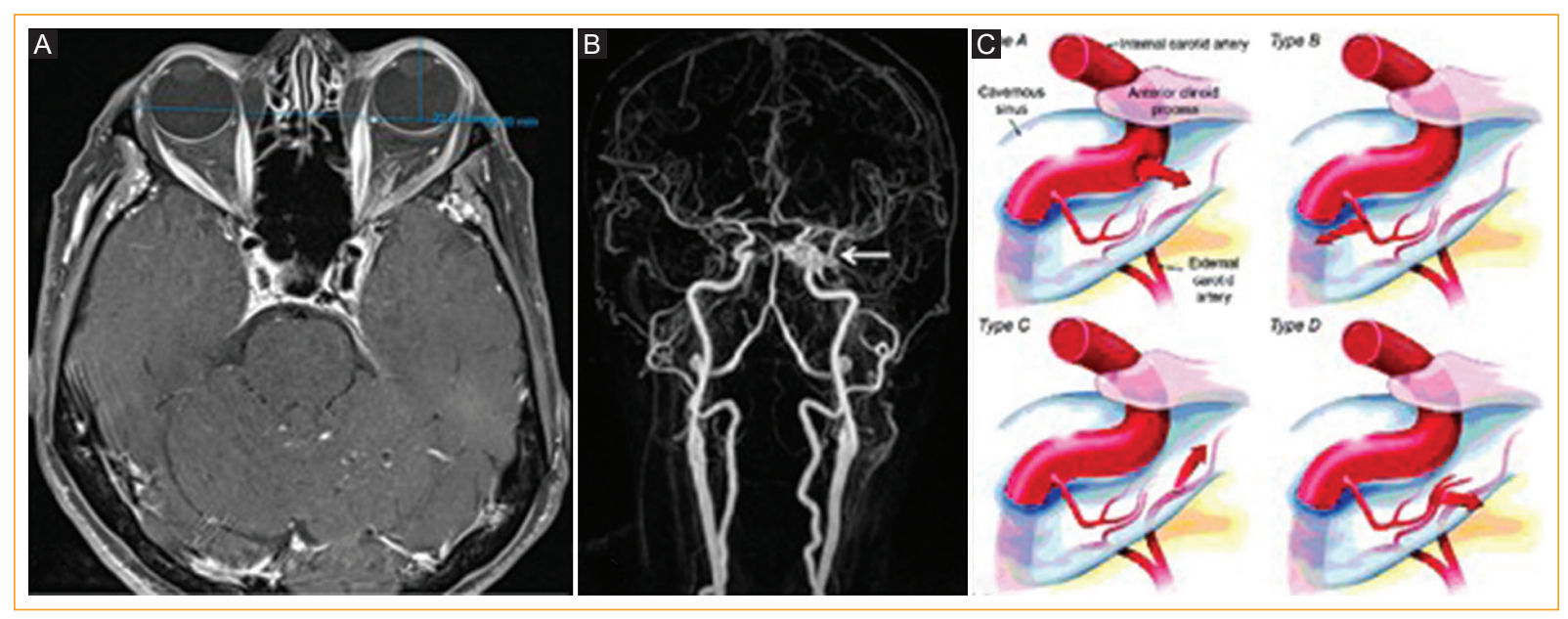

Figura 3. A: adquisición axial de resonancia magnética contrastada en secuencia T1 con saturación grasa. Se observa engrosamiento de los músculos extraoculares, principalmente del recto medial, y proptosis ocular izquierda de $22 \mathrm{~mm}$. B: angiorresonancia cerebral que muestra asimetría en el seno cavernoso izquierdo (flecha) y dilatación de la vena oftálmica superior izquierda. C: clasificación de Barrow de las fístulas carotidocavernosas (tomada de Ellis, et al. ${ }^{2}$.

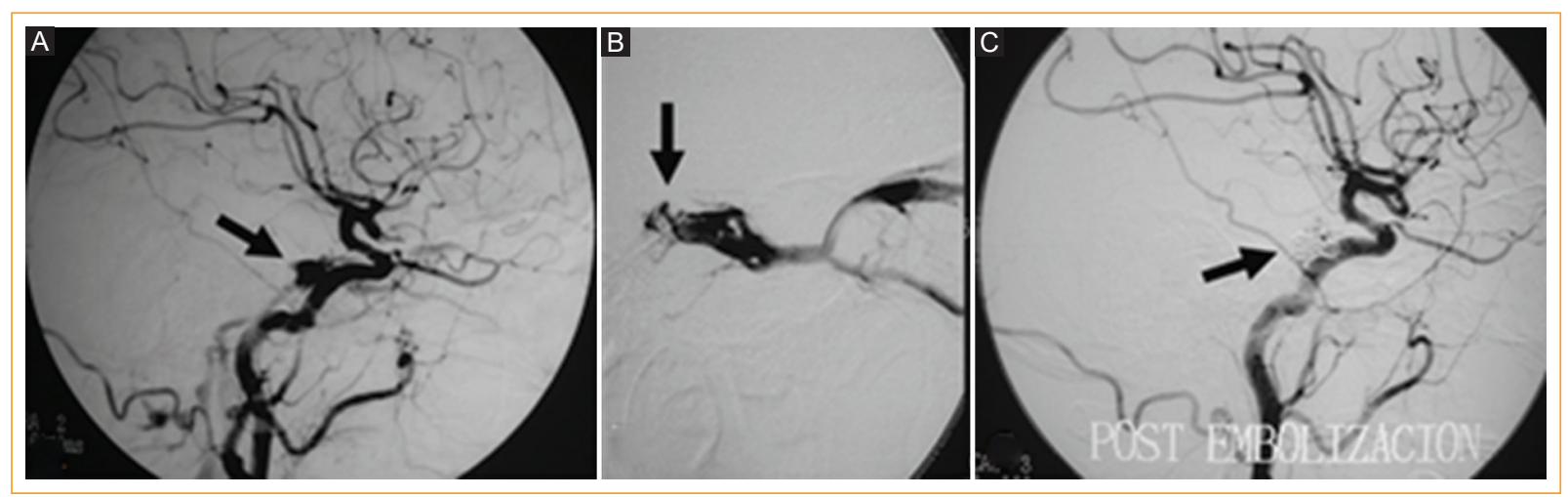

Figura 4. Angiografía cerebral. A: fístula carotidocavernosa de bajo flujo (flecha) nutrida por ramas durales del tronco meningohipofisiario de la carótida interna izquierda (Barrow tipo B). B: embolización con coils por vía venosa, a través del seno petroso inferior hasta el seno cavernoso. C: control angiográfico posterior a la embolización que muestra la completa oclusión de la fístula por los coils.

importante el uso complementario de imágenes diagnósticas y realizar un enfoque multidisciplinario que oriente al diagnóstico certero. En caso de discrepancias clinicorradiológicas, como en esta paciente, que mostraba limitación del recto lateral al examen físico (músculo con menos frecuencia implicado en la oftalmopatía tiroidea), cobra gran importancia considerar una revaloración de las imágenes por otros especialistas, en especial cuando no hay mejoría con el tratamiento.

\section{Conclusión}

El diagnóstico de proptosis es un reto en oftalmología. Hay que tener presente que, a pesar de ser la causa más frecuente, no siempre la proptosis se debe a una oftalmopatía distiroidea. Cuando los signos son inusuales se debe pensar en diagnósticos diferenciales ${ }^{6}$, como en el caso presentado, en el que había limitación en el recto lateral en la evaluación de la motilidad ocular, hallazgo infrecuente en la orbitopatía tiroidea $^{1,5,7,8}$. 


\section{Conflicto de intereses}

Las autoras declaran no tener ningún conflicto de intereses.

\section{Responsabilidades éticas}

Protección de personas y animales. Las autoras declaran que los procedimientos seguidos estuvieron en conformidad con las normas éticas y de acuerdo con la Asociación Médica Mundial y la Declaración de Helsinki.

Confidencialidad de los datos. Las autoras declaran que han seguido los protocolos de su centro de trabajo sobre la publicación de datos de pacientes.

Derecho a la privacidad y consentimiento informado. Las autoras han obtenido el consentimiento informado de la paciente referida en el artículo.
Este documento obra en poder de la autora de correspondencia.

\section{Bibliografía}

1. Barrow DL, Spector RH, Braun IF, Landman JA, Tindall SC, Tindall GT. Classification and treatment of spontaneus carotid-cavernous sinus fistulas. J Neurosurg. 1985;62:248-56.

2. Ellis J, Goldstein H, Connolly E, Meyers P. Carotid-cavernous fistulas. Neurosurg Focus. 2012;32:E9.

3. Micieli JA, Bedi H, Krings T. A woman with a red eye from a carotidcavernous sinus fistula. CMAJ. 2017:189:113-5.

4. Abecassis IJ, Morton RP, Kim LJ, Ghodke BV, Levitt MR. Combined direct and indirect traumatic carotid-cavernous fistula (CCF): case report and review of the literature. J Clin Neurosci. 2017;44:240-2.

5. Rootman J Orbital inflammatory disease, orbital disease, present status and future challenges. 4th ed. Boca Raton: Taylor and Francis; 2005.

6. Buerger DG. Proptosis. En: Gault JA, editor. Ophthalmology secrets in color. 4th ed. Philadelphia: Elsevier; 2016. p. 278-81.

7. Yanoff, M. Ophthalmology. 4th ed. Philadelphia: Elsevier; 2014.

8. Mombaerts I, Bilyk JR, Rose GE, McNab AA, Fay A, Dolman PJ, et al. Consensus on diagnostic criteria of idiopathic orbital inflammation using a modified Delphi approach. JAMA Ophthalmol. 2017;135:769-76.

9. Morris P. Practical neuroangiography. 3rd ed. Philadelphia: Wolters Kluwer Health; 2013.

10. Gonzales L. Neurointerventional techniques. New York: Thieme; 2014 